\title{
POLA SEBARAN TUMBUHAN INVASIF DIKAWASAN TAMAN NASIONAL BUKIT SULAP KOTA LUBUKLINGGAU
}

\author{
Nopa Nopiyanti ${ }^{1}$, Reni Dwi Riastuti ${ }^{2}$ \\ STKIP PGRI Lubuklinggau ${ }^{1,2}$ \\ nopachandra@gmail.com ${ }^{1}$
}

\begin{abstract}
ABSTRAK
Tujuan penelitian ini adalah mengetahui jenis-jenis tumbuhan invasif yang ada di kawasan TNKS Bukit Sulap dan mengetahui pola sebaran tumbuhan invasif. Hasil penelitian yang diperoleh dari 8 plot ditemukan 35 species dari 25 famili tumbuhan invasif, pola penyebaran tumbuhan invasif acak yaitu pada tumbuhan Phyllanthus urinaria (Meniran), Graptophyllum pictum L (Daun Ungu), Nephrolepis biserrata (Paku Pedang), Elais guneensis J (Sawit), Baccaureamotleyana (Rambe), Cassia Alata (Ketepeng Cina), Acacia auricuformis (akasia), Alpinia maccensis (Lengkuas hutan), Paraserianthes falcataria (Sengon), Clibadium surinamense (Clibadium), Gynura divaricata (Daun dewa), Urena lobata (Pulutan), Piper aduncum (Sirihan), Setaria sphacelata (Rumput setaria), Asplenium nidus (Paku sarang burung), Averhoa carambola.L (Belimbing), Artocarpus heterophyllus (Nangka). Simpulan, tingkat pola penyebaran tumbuhan invasif seragam tertinggi yaitu pada tumbuhan Calamus rotang (Rotan), Chromolaena odorata (daun kiri nyuh), Diplazium esculentum s (Pakis), Talipariti tiliaceum (Waru) sebesar -0,14. Pola penyebaran tumbuhan invasif seragam terendah yaitu pada tumbuhan Cenchrus purpureus (Rumput gajah) sebesar -5,86.
\end{abstract}

Kata Kunci: bukit sulap, invasif, pola sebaran, tumbuhan,

\begin{abstract}
The purpose of this study was to determine the types of invasive plants that exist and to find out the pattern of invasive plant distribution. Research results obtained from 8 plots found 35 species from 25 invasive plant families, random invasive plant distribution patterns, namely in Phyllanthus urinaria (Meniran), Graptophyllum pictum L (Purple Leaf), Nephrolepis biserrata (Sword Spikes), Elais guneensis J (Sawit), Baccaureamotleyana (Rambe), Cassia Alata (Chinese Ketepeng), Acacia auricuformis (acacia), Alpinia maccensis (galangal forest), Paraserianthes falcataria (Sengon), Clibadium surinamense (Clibadium), Gynura divaricata (Leaf of god), Urena lobal (Pulutan lobus) ), Piper aduncum (Sirihan), Setaria sphacelata (Setaria grass), Asplenium nidus (Bird's nest nails), Averhoa carambola.L (Star fruit), Artocarpus heterophyllus (Jackfruit). Conclusion, the highest level of spread pattern of invasive plants is Calamus rotang (Rattan), Chromolaena odorata (left leaf nyuh), Diplazium esculentum s (Fern), Talipariti tiliaceum (Waru) of -0.14. The lowest uniform pattern of invasive plant spread is Cenchrus purpureus (elephant grass) at -5.86.
\end{abstract}

Keywords: sulap Hill, invasive, distribution pattern, Plants 


\section{PENDAHULUAN}

Tumbuhan invasif adalah semua jenis tumbuhan yang telah menyebar ke dalam suatu komunitas dan menyebabkan gangguan terhadap jenis tumbuhan lain. Tumbuhan invasif memiliki adaptasi yang baik di habitat baru, sehingga dapat mempertahankan populasinya dengan baik dan menyebabkan kerusakan lingkungan (Tjitrosoedirdjo, 2012).

Menurut Supriatna (2008), kerusakan lingkungan yang ditimbulkan oleh tumbuhan invasif yaitu ancaman terhadap kelestarian keanekaragaman hayati, gangguan terhadap jenis tumbuhan yang terancam punah, dapat mengubah habitat, mengubah proses ekologi alami (suksesi) tumbuhan, dan mengganggu asosiasi tumbuhan dengan hewan. Contoh tumbuhan invasif di Indonesia adalah Imperata cylindrica, Lantana camara, Acacia nilotica, dan Clidemia hirta. Informasi ini mengacu kepada database jenis tumbuhan invasif di Indonesia yang dikumpulkan oleh Biotrop (2008).

The Invasive Species Advisory Committee (ISAC) (2006) Invasive Alien Spesies atau tumbuhan asing invasif merupakan jenis yang mengintroduksi ke dalam ekosistem lain dan menyebabkan kerugian ekonomi, kerusakan lingkungan serta dapat membahayakan kesehatan manusia. Studi mengenai spesies yang diintroduksi atau spesies yang berasal dari luar belum banyak dilakukan di Indonesia. Data mengenai spesies asing di Indonesia tersedia dalam jumlah yang terbatas.

Salah satu taman nasional yang berpotensi memiliki tanaman invasif adalah Taman Nasional Bukit Sulap, Kota Lubuklinggau. Beberapa lokasi di taman nasional tersebut perlu diidentifikasi keberadaan tumbuhan invasif. Tujuan penelitian ini adalah mengetahui jenis-jenis tumbuhan invasif yang ada di kawasan TNKS Bukit Sulap Kota Lubuklinggau dan mengetahui pola sebaran tumbuhan invasif di Bukit Sulap Kota Lubuklinggau.

\section{METODE PENELITIAN}

\section{Rancangan Penelitian}

Metode dalam penelitian ini adalah metode deskriptif kualitatif. Penelitian deskriptif bertujuan untuk menjelaskan atau mendeskripsikan suatu keadaan atau peristiwa, objek, apakah orang atau semua yang terkait dengan variabel yang bisa dijelaskan baik dengan angka maupun kata-kata (Setyosari, 2015).

\section{Prosedur Penelitian}

\section{Lapangan}

Dilakukan pengambilan sampel jenis yang diperkirakan termasuk tumbuhan invasif yang terdapat di kawasan bukit sulap dilakukan dengan menjelajah lokasi penelitian serta mencatat sampel yang telah ditemukan di lapangan yang meliputi nama species, morfologi tanaman serta faktr ekologi. Setiap sampel difoto dan dibuat herbarium, kemudian specimen di beri label 
gantung dan dimasukan kedalam kantong besar. Data ekologi juga dicatat seperti suhu udara, kelembaman udara, ketinggian tempat.

\section{Laboratorium}

1. Pembuatan Herbarium. Setelah sampel di kumpulkan selanjutnya sampel dibuat herbarium yaitu herbarium kering yang dapat digunakan sebagai bahan pengamatan mengenai morfologi dati tanaman invasif dan dapat berguna sebagai bukti ilmiah yang dapat disimpan dalam kurun waktu yang lama. Langkah-langkah pembuatan herbarium menurut Tjitrosoepomo (2009) adalah sebagai berikut:

a. Sampel yang dikumpulkan dari lapangan dibersihkan terlebih dahulu dengan air dengan cara di cuci.

b. Sampel yang telah terkumpul dan telah diberi label gantung, kemudian direndam dengan alkohol kira-kira 10 menit.

c. Specimen/sampel diangkat kemudian diletakan di atas koran satu perssatu dan disusun sedemikian rupa.

d. Setelah seluruh specimen dimasukan kedalam kertas koran, specimen dijepit dengan papan triplek dan diikat dengan menggunakan tali rapia, bagian atas dan bagian bawahnya yang bertujuan agar specimen tidak terlipat atau bergeser selama pengepresan.

e. Setelah itu specimen disimpan dalam jangka waktu 3-4 hari

f. Setelah beberapa hari kemudian, specimen dibuka dan diangin-anginkan untu memperoleh hasil yang lebih sempurna

g. Setalah specimen diangin-anginkan, specimen tadi dimasukkan ke dalam album dan diberi label yang berisi data-data "tumbuhan invasif" seperti data taksonomi (nama species), nama kolektor, lokasi, dan tanggal koleksi.

h. Specimen siap dijadikan herbarium.

2. Identifikasi setiap sampel. Pengidentifikasian dengan menggunakan buku panduan karangan Gembong Tjitrosoepomo tahun 2011 dan Van Steenis, et al tahun 2008.

\section{Teknik analisis data}

Analisis data dilakukan dengan menggunakan metode deskriptif kaulitatif berdasarkan ciri-ciri morfologi, dan dilanjutkan dengan metode deskripstif kuantitafi untuk menghitung pola sebaran tumbuhan menggunakan indeks morisita. Data hasil penelitian disajikan dalam bentuk tabel.

\section{Indeks Morisita}

$$
I \delta=\frac{x-N}{(n-1)}
$$


Keterangan:

$$
\begin{aligned}
& \text { I } \delta=\text { indeks distribusi morisitas } \\
& \mathrm{N}=\text { jumlah seluruh individu } \\
& \mathrm{n}=\text { jumlah seluruh stasiun pengambilan sampel }
\end{aligned}
$$

Nilai indeks morisita yang diperoleh diinterprestasikan sebagai berikut:

I $\delta<1$, berarti penyebaran individu cenderung acak

I $\delta=1$, berarti penyebaran individu cenderung merata, dan

I $\delta>1$, berarti penyebaran individu cenderung berkelompok

\section{HASIL PENELITIAN}

Perbandingan jenis tumbuhan invasif yang terdapat pada setiap plot yang

\begin{tabular}{|c|c|c|c|c|c|c|c|c|}
\hline \multirow[t]{2}{*}{ Species } & \multicolumn{8}{|c|}{ Jumlah individu dalam plot } \\
\hline & 1 & 2 & 3 & 4 & 5 & 6 & 7 & 8 \\
\hline 1. Ageratum conyzoides $L$. & & 15 & 2 & & & & 7 & \\
\hline 2. Acacia auricuiformis & & & & & 1 & & & \\
\hline 3. $\quad$ Alpinia malaccenis & & & & & & & & 1 \\
\hline 4. $\quad$ Aspelium nidus & & & & & & 1 & & \\
\hline 5. Averhoa carambola & & & & & & 2 & & \\
\hline 6. Artocarpus heterophyllus & & & & & & 1 & & \\
\hline 7. $\quad$ Baccaureamot leyana & 1 & & & & & & & \\
\hline 8. $\quad$ Borriera latifolia & & 25 & 3 & & & & & 9 \\
\hline 9. Brachiaria decumbens & 9 & 15 & 2 & 12 & & & & \\
\hline 10. Climbadium surimaNense & & & 1 & & & & & \\
\hline 11. Cayratia trifolia & & 4 & 3 & & & & & \\
\hline 12. Cyperus ritundus $L$. & 12 & & 3 & & & & & \\
\hline 13. Calamus rotang & & & 1 & & & 2 & & \\
\hline 14. $\quad$ Clidemia hirta & 5 & 5 & & 4 & 5 & 8 & & \\
\hline 15. Cenchrus purpureus & & & & 18 & & & 21 & \\
\hline 16. Coffea Arabia & 4 & & & 5 & 1 & 3 & & 1 \\
\hline 17. Cassia alata & & & & & 1 & & & \\
\hline 18. Chromolaena odorata & & & & & 1 & & & \\
\hline 19. Diplazium esculentum $s p$ & 6 & 1 & 2 & & & & & 2 \\
\hline 20. Elais guineensis & 1 & & & & & & & \\
\hline 21. Graptophyllum pictum & 23 & & & & & & & \\
\hline 22. Gynura divaricata & & & & 9 & & & & \\
\hline 23. Mimosa pidosa & & & & & & & & 10 \\
\hline 24. Mikania micrantha & & & & 9 & & & & 6 \\
\hline 25. Nephrolopis cordifolia & 8 & & & & 8 & & & 3 \\
\hline 26. Nephrolepis biserrata & 8 & & & & & & & \\
\hline 27. Phyllanthus urinaria & & & & & & & 5 & \\
\hline 28. Piper aduncum & & & & 2 & & & & \\
\hline 29. Paraserioanthe sfalcataria & & & & & & & & 1 \\
\hline 30. Stachytarpheta jamaicensis & & 5 & 1 & & & & 8 & 4 \\
\hline 31. Selaginella $s p$ & 4 & 5 & 4 & & & & 4 & \\
\hline $\begin{array}{l}\text { 32. Stenochlaena } \\
\text { Palustri }\end{array}$ & & 15 & & & & & & \\
\hline
\end{tabular}
diteliti dapat dilihat pada Tabel 1

Tabel.1 Tumbuhan Invasif dalam Setiap Plot 


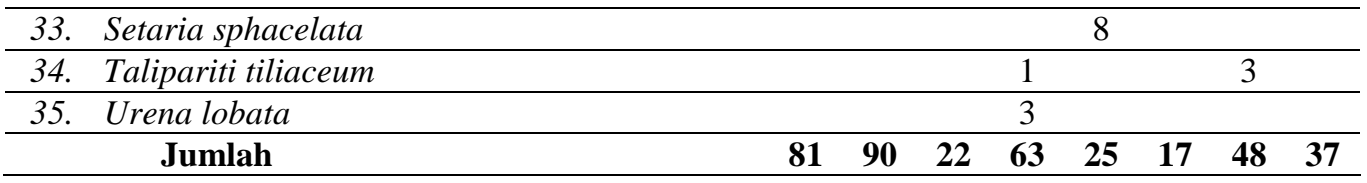

Hasil penelitian menunjukkan bahwa jumlah spesies tumbuhan asing invasif yang ditemukan antar plot berbeda, dapat dilihat tabel 1. Berdasarkan tabel 1 dapat diketahui bahwa spesies invasif terbanyak terdapat pada plot 2 dengan jumlah 90 spesies. Dari 8 plot ditemukan 35 species dari 25 famili tumbuhan invasif. Jenis tumbuhan yang jumlah individunya paling banyak ditemukan adalah Rumput Gajah (Cenchrus purpureus).

Tabel.2 Persebaran Tumbuhan Invasif dalam Setiap Plot

\begin{tabular}{|c|c|c|c|c|c|c|c|c|c|}
\hline \multirow[t]{2}{*}{ No } & \multirow[t]{2}{*}{ Spesies } & \multicolumn{8}{|c|}{ Jumlah Individu dalam plot } \\
\hline & & 1 & 2 & 3 & 4 & 5 & 6 & 7 & 8 \\
\hline 1 & $\begin{array}{l}\text { Stachytarpheta jamaicensis } \\
\text { (Pecut Kuda) }\end{array}$ & - & $\begin{array}{l}-1,84 \\
(\mathrm{~S})\end{array}$ & $\begin{array}{c}-2,43 \\
(S)\end{array}$ & - & - & - & $\begin{array}{c}-1,43 \\
(S)\end{array}$ & $-2(\mathrm{~S})$ \\
\hline 2 & $\begin{array}{l}\text { Phyllanthus urinaria } \\
\text { (Meniran) }\end{array}$ & - & - & - & - & - & - & $0(\mathrm{~A})$ & - \\
\hline 3 & Mimosa pidosa (putri malu) & $\begin{array}{c}-3,43 \\
\text { (S) }\end{array}$ & $\begin{array}{c}-3,43 \\
(\mathrm{~S}) \\
\end{array}$ & - & - & - & - & $\begin{array}{c}-1,71 \\
(\mathrm{~S})\end{array}$ & $\begin{array}{c}- \\
2,14(\mathrm{~S})\end{array}$ \\
\hline 4 & $\begin{array}{l}\text { Ageratum conyzoides } L . \\
\text { (Bandotan) }\end{array}$ & - & $\begin{array}{l}-1,71 \\
(\mathrm{~S})\end{array}$ & $\begin{array}{l}-3,57 \\
(S)\end{array}$ & - & - & - & $\begin{array}{l}-2,43 \\
(S)\end{array}$ & - \\
\hline 5 & $\begin{array}{l}\text { Cenchrus purpureus (rumput } \\
\text { gajah) }\end{array}$ & & $\begin{array}{l}-5,57 \\
(\mathrm{~S})\end{array}$ & & $\begin{array}{l}-5,86 \\
(\mathrm{~S})\end{array}$ & & & $\begin{array}{l}-5,43 \\
(S)\end{array}$ & - \\
\hline 6 & Selaginella sp (paku rane) & $\begin{array}{c}-1,86 \\
(\mathrm{~S})\end{array}$ & $\begin{array}{c}-1,71 \\
(\mathrm{~S})\end{array}$ & $\begin{array}{c}-1,86 \\
(\mathrm{~S})\end{array}$ & - & - & - & $\begin{array}{l}-1,86 \\
(\mathrm{~S})\end{array}$ & - \\
\hline 7 & Talipariti tiliaceum (waru) & - & - & - & $\begin{array}{c}-0,43 \\
(\mathrm{~S})\end{array}$ & - & - & $\begin{array}{c}-0,14 \\
(S)\end{array}$ & - \\
\hline 8 & $\begin{array}{l}\text { Graptophyllum pictum (daun } \\
\text { Ungu) }\end{array}$ & $0(\mathrm{~A})$ & - & - & - & - & - & - & - \\
\hline 9 & $\begin{array}{l}\text { Cyperus ritundus L. (runput } \\
\text { teki) }\end{array}$ & $\begin{array}{l}-0,43 \\
(\mathrm{~S})\end{array}$ & & $\begin{array}{l}-1,71 \\
(\mathrm{~S})\end{array}$ & - & - & - & - & - \\
\hline 10 & $\begin{array}{l}\text { Clidemia hirta (haredong } \\
\text { bulu) }\end{array}$ & $\begin{array}{l}-3,14 \\
(\mathrm{~S})\end{array}$ & $\begin{array}{c}-3,14 \\
(\mathrm{~S})\end{array}$ & & $\begin{array}{l}-3,28 \\
(S)\end{array}$ & $\begin{array}{l}-3,14 \\
(\mathrm{~S})\end{array}$ & $\begin{array}{l}-2,71 \\
(\mathrm{~S})\end{array}$ & - & - \\
\hline 11 & $\begin{array}{l}\text { Brachiaria decumbens } \\
\text { (rumput Bede) }\end{array}$ & $\begin{array}{c}-4,14 \\
(\mathrm{~S})\end{array}$ & $\begin{array}{c}-3,28 \\
(\mathrm{~S})\end{array}$ & $\begin{array}{l}-5,14 \\
(\mathrm{~S})\end{array}$ & $\begin{array}{c}-3,71 \\
(\mathrm{~S})\end{array}$ & - & - & - & - \\
\hline 12 & $\begin{array}{l}\text { Diplazium esculentum } s p \\
\text { (pakis) }\end{array}$ & $\begin{array}{c}-0,14 \\
(S)\end{array}$ & $\begin{array}{c}-0,86 \\
(S)\end{array}$ & - & - & - & - & - & - \\
\hline 13 & $\begin{array}{l}\text { Nephrolepis biserrata (Paku } \\
\text { Pedang) }\end{array}$ & $0(\mathrm{~A})$ & - & - & - & - & - & - & - \\
\hline 14 & Coffea Arabia L (Kopi) & $\begin{array}{l}-1,43 \\
(S)\end{array}$ & - & $\begin{array}{l}-1,28 \\
(\mathrm{~S})\end{array}$ & $\begin{array}{c}-1,86 \\
(\mathrm{~S})\end{array}$ & - & $\begin{array}{l}-1,57 \\
(\mathrm{~S})\end{array}$ & - & $\begin{array}{c}-1,86 \\
(\mathrm{~S})\end{array}$ \\
\hline 15 & Elais guineensis $J$ (Sawit) & $0(\mathrm{~A})$ & - & - & - & - & - & - & - \\
\hline 16 & $\begin{array}{l}\text { Baccaureamot leyana } \\
\text { (rambe) }\end{array}$ & $0(\mathrm{~A})$ & - & - & - & - & - & - & - \\
\hline 17 & $\begin{array}{l}\text { Cassia alata (Ketepeng } \\
\text { cina) }\end{array}$ & - & - & - & - & $0(\mathrm{~A})$ & - & - & - \\
\hline 18 & $\begin{array}{l}\text { Chromolaena odorata (daun } \\
\text { kiri nyuh) }\end{array}$ & - & - & - & - & $\begin{array}{c}-0,43 \\
(\mathrm{~S})\end{array}$ & - & - & $\begin{array}{l}-014 \\
(\mathrm{~S})\end{array}$ \\
\hline 19 & $\begin{array}{l}\text { Stenochlaena Palustri (paku } \\
\text { palustris) }\end{array}$ & - & $\begin{array}{l}-0,28 \\
(\mathrm{~S})\end{array}$ & - & - & $\begin{array}{c}-2,14 \\
(\mathrm{~S})\end{array}$ & - & - & - \\
\hline 20 & $\begin{array}{l}\text { Nephrolopis cordifolia (paku } \\
\text { nephrolopis) }\end{array}$ & - & - & - & - & $\begin{array}{c}-1,28 \\
(S)\end{array}$ & $\begin{array}{l}-1,57 \\
(\mathrm{~S})\end{array}$ & - & $-2(\mathrm{~S})$ \\
\hline
\end{tabular}




\begin{tabular}{|c|c|c|c|c|c|c|c|c|c|}
\hline 21 & $\begin{array}{l}\text { Acacia auricuiformis } \\
\text { (akasia) }\end{array}$ & - & - & - & - & 0 (A) & - & - & - \\
\hline 22 & $\begin{array}{l}\text { Alpinia malaccenis } \\
\text { (Lengkuas Hutan) }\end{array}$ & - & - & - & - & - & - & - & $0(\mathrm{~A})$ \\
\hline 23 & Mikania micrantha (rayutan) & - & - & - & $\begin{array}{c}0,86 \\
(\mathrm{~S})\end{array}$ & - & - & - & $\begin{array}{c}-1,28 \\
\text { (S) }\end{array}$ \\
\hline 24 & $\begin{array}{l}\text { Cayratia trifolia } \\
\text { (kasapan/galling) }\end{array}$ & - & $\begin{array}{l}-1,57 \\
(\mathrm{~S})\end{array}$ & $\begin{array}{l}-3,28 \\
(\mathrm{~S})\end{array}$ & - & - & - & - & $\begin{array}{c}-2,57 \\
(S)\end{array}$ \\
\hline 25 & $\begin{array}{l}\text { Borriera latifolia } \\
\text { (Kentangan) }\end{array}$ & - & $\begin{array}{l}-1,28 \\
(\mathrm{~S})\end{array}$ & - & - & - & - & - & $\begin{array}{c}-3,57 \\
(S)\end{array}$ \\
\hline 26 & $\begin{array}{l}\text { Diplazium esculentum sp } \\
\text { (paku sayur) }\end{array}$ & - & - & $\begin{array}{c}-0,28 \\
(\mathrm{~S})\end{array}$ & - & - & - & - & $\begin{array}{c}-0,28 \\
\text { (S) }\end{array}$ \\
\hline 27 & $\begin{array}{l}\text { Paraserioanthe sfalcataria } \\
\text { (sengon) }\end{array}$ & - & - & - & - & - & - & - & $0(\mathrm{~A})$ \\
\hline 28 & $\begin{array}{l}\text { Climbadium surinamense } \\
\text { (Clibadium) }\end{array}$ & - & - & $0(\mathrm{~A})$ & - & - & - & - & - \\
\hline 29 & $\begin{array}{l}\text { Gynura divaricata (daun } \\
\text { dewa) }\end{array}$ & - & - & - & $0(\mathrm{~A})$ & - & - & - & - \\
\hline 30 & Urena lobata (pulutan) & & & & $0(\mathrm{~A})$ & - & - & - & - \\
\hline 31 & Piper aduncum (Sirihan) & - & - & - & - & - & - & - & - \\
\hline 32 & $\begin{array}{l}\text { Setaria sphacelata (rumput } \\
\text { setaria) }\end{array}$ & - & - & - & - & 0 (A) & - & - & - \\
\hline 33 & Calamus rotang (rotan) & - & - & $\begin{array}{l}-0,28 \\
(\mathrm{~S})\end{array}$ & - & - & $\begin{array}{l}-0,14 \\
(\mathrm{~S})\end{array}$ & - & - \\
\hline 34 & $\begin{array}{l}\text { Asplenium Nidus (paku } \\
\text { sarang burung) }\end{array}$ & - & - & - & - & - & $0(\mathrm{~A})$ & - & - \\
\hline 35 & $\begin{array}{l}\text { Averhoa Carambola L } \\
\text { (Belimbing) }\end{array}$ & - & - & - & - & - & $0(\mathrm{~A})$ & - & - \\
\hline 36 & $\begin{array}{l}\text { Artocarphus heterophyllus } \\
\text { (Nangka) }\end{array}$ & - & - & - & - & - & $0(\mathrm{~A})$ & - & - \\
\hline
\end{tabular}

Keterangan :

$S$ : Seragam (mengelompok)

A : Acak

\section{PEMBAHASAN}

Hasil penelitian menunjukkan bahwa jumlah spesies tumbuhan asing invasif yang ditemukan antar plot berbeda, dapat dilihat tabel 1. Berdasarkan tabel 1 dapat diketahui bahwa spesies invasif terbanyak terdapat pada plot 2 dengan jumlah 90 spesies. Dari 8 plot ditemukan 35 species dari 25 famili tumbuhan invasif.

Jenis tumbuhan yang jumlah individunya paling banyak ditemukan adalah Rumput Gajah (Cenchrus purpureus). Tumbuhan ini mempunyai akar yang mudah tumbuh di buku-buku dari batang yang merayap di dalam tanah dan dimana keberadaan akar tanah akan mempercepat penutupan tanah sehingga akan tumbuh memperluas rumput gajah, dikaitkan dengan kedaan tanah yang subur dan kelmbapan tanahnya sehingga kebutuhan mineral yang diperlukan tumbuhan itu terpenuhi, dan alasan inilah yang memicu sehingga lebih merata banyaknya di kawasan bukit sulap ini ditumbuhi oleh rumput gajah.

Jumlah individu paling sedikit terdapat pada tumbuhan sawit (Elais guineensis), rambe (Baccaure amotleyana), ketepeng cina (Cassia alata), daun 
kiri nyuh (Chromolaena odorata), akasia (Acacia auricuformis), lengkuas hutan (Alpinia malaccencis), sengon (Paraserioanthes falcataria), clibadium ( Clibadium surinamense), paku sarang burung ( Asplenium nidus), dan nangka ( Artocarpus heterophyllus), karena kondisi dari setiap kawasan tanah yang ada di kawasan bukit sulap tersebut berbeda-beda dan pada kebutuhan mineral yang dibutuhkan tanaman tersebut berbeda-beda sehingga pada jenis tumbuhan invasif sedikit itulah memungkinkan kurangnya atau tidak terpenuhinya kebutuhan yang dibutuhkan tanaman tersebut untuk tumbuh dan menyebar luas menjadi banyak.

Berdasarkaan tabel 2 hasil dari total keseluruhan diperoleh pola penyebaran tumbuhan invasif Acak yaitu pada tumbuhan Phyllanthus urinaria (Meniran), Graptophyllum pictum L (Daun Ungu), Nephrolepis biserrata (Paku Pedang), Elais guineensis J (Sawit), Baccaureamotleyana (Rambe), Cassia alata (ketepeng cina), Acacia auricuiformis (akasia), Alpinia malaccensis (Lengkuas Hutan), Paraserioanthes falcataria (Sengon), Clibadium surinamense (Clibadium), Gynura divaricata (Daun dewa), Urena lobata (Pulutan), Piper aduncum (Sirihan), Setaria sphacelata (Rumput setaria), Asplenium nidus (Paku sarang burung), Averhoa carambola.L (Belimbing), Artocarpus heterophyllus (Nangka).

Pola penyebaran tumbuhan invasif seragam tertinggi yaitu pada tumbuhan Calamus rotang (Rotan), Chromolaena odorata (daun kiri nyuh), Diplazium esculentum s (Pakis), Talipariti tiliaceum (Waru) sebesar -0,14. Pola penyebaran tumbuhan invasif seragam terendah yaitu pada tumbuhan Cenchrus purpureus (Rumput gajah) sebesar -5,86. Pola distribusi yang terjadi secara mengelompok menunjukkan angka kematian yang lebih rendah jika keadaan lingkungan tidak menguntungkan, bila dibandingkan dengan individu yang menyebar secara acak atau merata (Kurniawati 2008).

Tjitrosoedirdjo (2013) menjelaskan kriteria tumbuhan yang dikatakan invasif diantaranya cepat membangun naungan yang lebat, bersifat "different phenology" tumbuh lebih dahulu dan hijau lebih lama, dan biasanya spesies tersebut tidak memiliki musuh alami yang dapat mengendalikan pertumbuhan populasinya.

Penyebaran merupakan parameter kualitatif yang menggambarkan keberadaan spesies organisme baik tumbuhan atau pun satwa pada ruang horizontal (Indriyanto 2006). Pola distribusi mengelompok terjadi sebagai akibat adanya sifat yang sama dari habitat maupun faktor abiotik dalam mendukung tumbuhan invasif untuk tumbuh. Sehingga, bagi beberapa tumbuhan asing invasif akan memiliki tingkat pertahanan hidup yang tinggi pada tempat tumbuhnya. 


\section{SIMPULAN}

Tingkat pola penyebaran tumbuhan invasif seragam tertinggi yaitu pada tumbuhan Calamus rotang (Rotan), Chromolaena odorata (daun kiri nyuh), Diplazium esculentum s (Pakis), Talipariti tiliaceum (Waru) sebesar -0,14. Pola penyebaran tumbuhan invasif seragam terendah yaitu pada tumbuhan Cenchrus purpureus (Rumput gajah) sebesar $-5,86$.

\section{DAFTAR PUSTAKA}

Biotrop. (2008). Database Seameo Biotrop Shoutheast Asian Regional Center For Tropical Biology. Bogor, Indonesia.Http://www.biotrop.org/database. php?act $=$ dbias\&kategori $=\&$ page $=8$. Tanggal akses 01 Juni 2013.

Indrawan, M., Primack, R., \& Supriatna, J. (2007). Biologi Konservasi. Terjemahan dari A Primer of Conservation Biology, oleh Richard B. Primack, Yayasan Obor Indonesia, Jakarta

Invasive species advisory committae. (2006). Invasive species definition and clarification and guidance. National invasive species council. http://www.issg.org/database.(15 februari 2015).

Kurniawati E. (2008). Perbedaan komposisi komunitas gulma pada area perkebunan teh rakyat dengan kanopi tertutup di daerah pagilaran batang. [skripsi]. Semarang (ID): IKIP PGRI

Steenis, V.(2013). Flora. Jakarta: PT. Pradnya Paramita.

Susanti,T. Suraida \& Febriana,H. (2013). Keanekaragaman Tumbuhan invasif di kawasan taman hutan kenali kota jambi. Prosiding semirata FMIPA universitas lampung tahun 2013.

Supriatna, J. (2008). Melestarikan Alam Indonesia. Yayasan Obor Indonesia, Jakarta.

Tjitrosoedirdjo, S. (2012). The Concept of Invasive Alien Species. Lecture Note Regional Training Course on The Managemen of Invasive Alien Plant. Seamoe Biotrop, Bogor.

Tjirosoedirdjo S. (2013). Ekologi Invasi. Pelatihan analisis resiko, deteksi dini, dan langkah cepat penanggulangan tumbuhan asing invasif di ekosistem hutan tahun 2013 November 27-30; Bogor, Indonesia . Bogor (ID): Seameo Biotrop

Zaman. (2009). Media dan Sumber Belajar. Jakarta: universitas terbuka. 